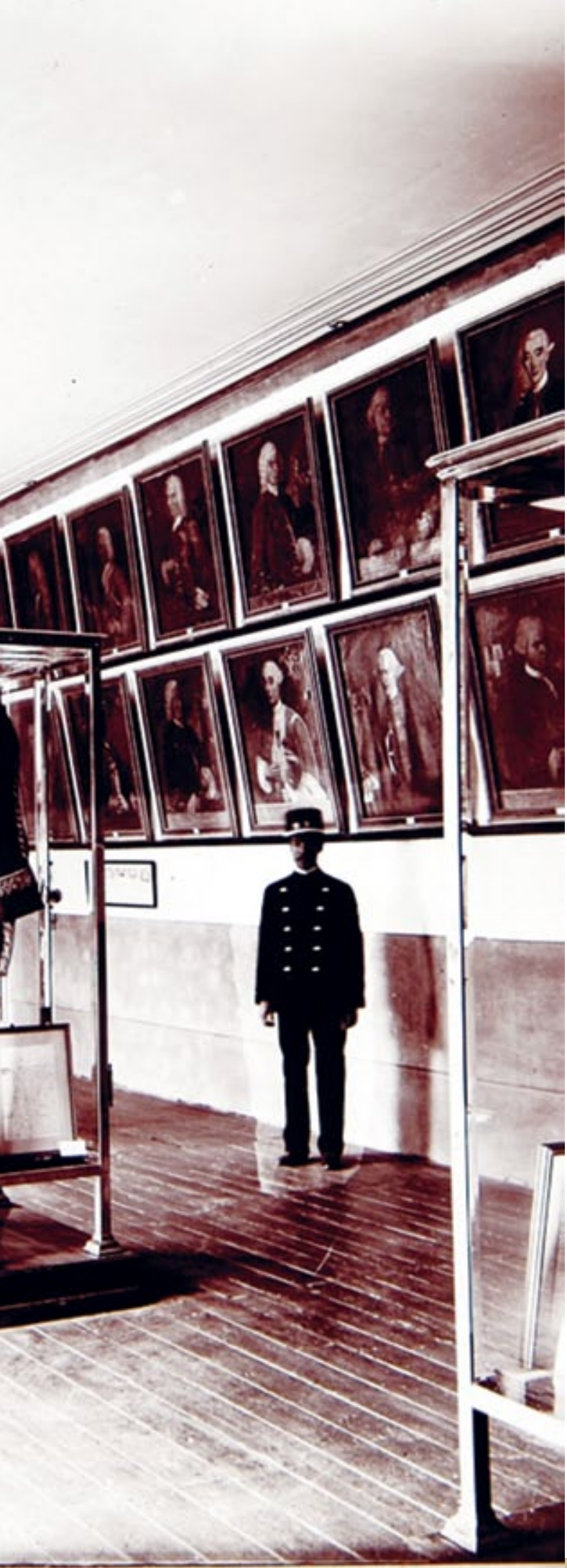

\title{
Continente/contenido: nuevos reflejos sobre las vitrinas del antiguo Museo Nacional
}

\author{
Adriana Ramírez Galván
}

$\mathrm{n}$ fechas recientes, el Museo Nacional de las Culturas (MNC) del Instituto Nacional de Antropología e Historia (INAH) ha sido sometido a una compleja reestructuración, proceso durante el cual la intervención de bienes culturales de su rico acervo, conformado principalmente por objetos de diversos pueblos del mundo, representa una tarea fundamental. De ahí que la Coordinación Nacional de Conservación del Patrimonio Cultural (CNCPC) del INAH y un equipo de restauradores asignados al museo realizaran diversas acciones de conservación-restauración, ${ }^{1}$ cuya finalidad consistió tanto en preservar los valores del patrimonio cultural del MNC como en incorporar nuevos elementos a sus salas de exhibición como parte de una renovada museografía, todo ello encaminado a promover la instrucción y el deleite de los numerosos visitantes de una institución paradigmática en la historia de nuestro país.

El desarrollo de esta iniciativa de conservación-restauración en el MNC, ubicado en el corazón del Centro Histórico de la ciudad de México, no sólo desveló la trascendencia de sus acervos, así como nuevos datos en torno de la historia, el contexto cultural y la valoración de sus colecciones, sino adicionalmente recuperó significativas evidencias sobre la historia expositiva del lugar. Un ejemplo claro de esto último fue una serie de vitrinas que originalmente pertenecieron al antiguo Museo Nacional de Arqueología, Historia y Etnografía ${ }^{2}$ (MNAHE), las cuales son el objeto de este escaparate (Figura 1).

El conjunto está compuesto por 18 piezas de gran formato en metal y vidrio. Su uso primigenio llama la atención, ya que conformaban parte del apoyo museográfico de las salas de exhibición permanente del MNAHE a finales del siglo XIX y principios del siglo XX (Figura 2). Aunque no se cuenta con información precisa, este mobiliario se mantuvo en uso hasta la década de 1940, cuando varias salas del museo se desmontaron para reubicar gran

${ }^{1}$ En esta iniciativa, coordinada y supervisada por quien suscribe, participaron las restauradoras Damaris Aguilar Jiménez, Laura I. Martínez Rodríguez, Berenice Mejía Maldonado y Patricia Ruiz Portilla, quienes se encargaron del registro, intervención y documentación de la obra. 2 Para mayores datos sobre la historia de esta institución museística, véase V.V. A.A. (2001). 


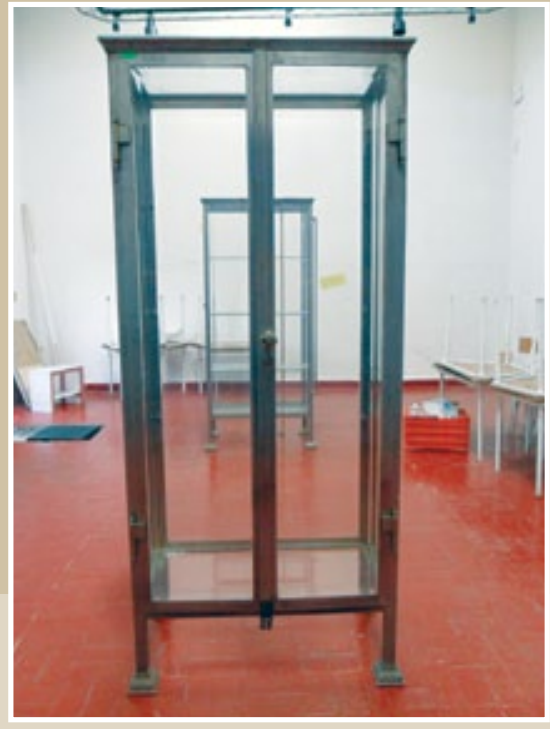

FIGURA 1. Vista general de una de las vitrinas en su estado en 2011 (Cortesía: Proyecto Conservación y Restauración de las Colecciones del Museo Nacional de las Culturas en el Marco de su Reestructuración 2010-2011, CNCPC-INAH, 2011).

parte de sus colecciones en varios museos nacionales del INAH ${ }^{3}$ y otras instituciones museísticas del país.

Desde entonces las vitrinas se almacenaron sin que se les diera mayor atención, lo cual si bien resultó acertado porque los bienes se han preservado hasta la actualidad, difícilmente indica cuál era el reconocimiento y la valoración asignados a estos objetos. El presente, sin embargo, ha vuelto la mirada hacia ellos para plantear un reposicionamiento que ya ha influido en su intervención técnica, material y conceptual.

Desde el punto de vista técnico, vale la pena mencionar que para precisar la toma de decisiones sobre la conservación-restauración de las vitrinas, el equipo de restauración asignado al MNC-INAH decidió emplear la misma metodología aplicada con otros elementos de la colección intervenidos durante la temporada 2011. Para iniciar, se realizó un re-

${ }^{3}$ Incluidos los museos nacionales de Historia, de Antropología y del Virreinato.

FIGURA 2. Vitrinas en la Sala de Historia en el Museo Nacional de Arqueología, Historia y Etnografía (Fotografía: Autor no identificado, circa 1905; cortesía: Sistema Nacional de Fototecas (SINAFO) del INAH, número de inventario 42464912).

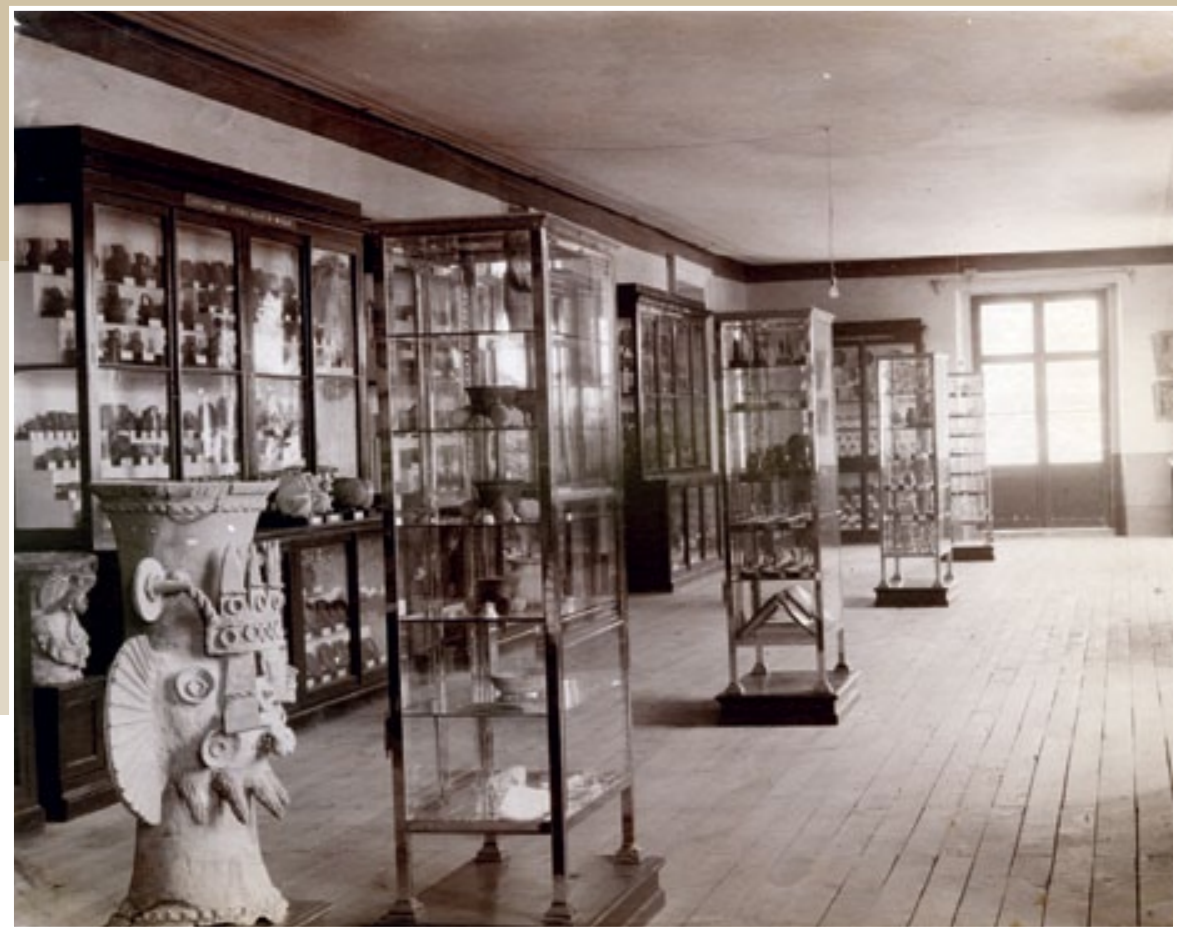

gistro general de la obra con base en la observación de su materialidad, con lo que se identificaron evidencias sobre su construcción (Figura 3). Posteriormente, se hizo un diagnóstico del estado físico de las piezas, el que sirvió para definir acciones y prioridades de atención. Debido a la gran cantidad de vitrinas que se conservan, al tiempo disponible para su intervención y a los recursos con los que se contaba, se optó por dar tratamiento completo a sólo dos de ellas (Ramírez Galván, Aguilar Jiménez, Martínez Rodríguez, Mejía Maldonado y Ruiz Portilla 2011).

La intervención material de las vitrinas se centró en optimizar tanto su estabilización como su aspecto, ambos afectados por diversas alteraciones. A causa de un prolongado almacenaje en condiciones no controladas, el conjunto de las superficies presentaba concentraciones de polvo, partículas contaminantes de todo tipo, restos orgánicos (cadáveres de insectos), manchas y pedazos de cintas adhesivas (Figura 4). Notablemente, las estructuras metálicas en su totalidad, por su propia

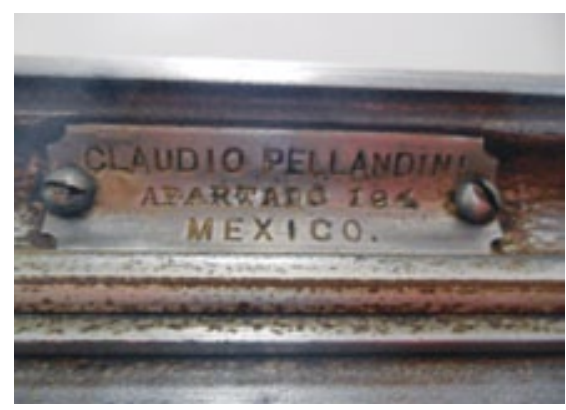

FIGURA 3. Troquelado metálico que registra datos de factura de las vitrinas (Cortesía: Proyecto Conservación y Restauración de las Colecciones del Museo Nacional de las Culturas en el Marco de su Reestructuración 20102011, CNCPC-INAH, 2011). 
FIGURA 4. Concentración de polvo y alteraciones físicas en uno de los bienes culturales intervenidos (Cortesía: Proyecto Conservación y Restauración de las Colecciones del Museo Nacional de las Culturas en el Marco de su Reestructuración 2010-2011, CNCPC-INAH, 2011).
FIGURA 5. Estructura metálica corroída (Cortesía: Proyecto Conservación y Restauración de las Colecciones del Museo Nacional de las Culturas en el Marco de su Reestructuración 2010-2011, CNCPC-INAH, 2011).
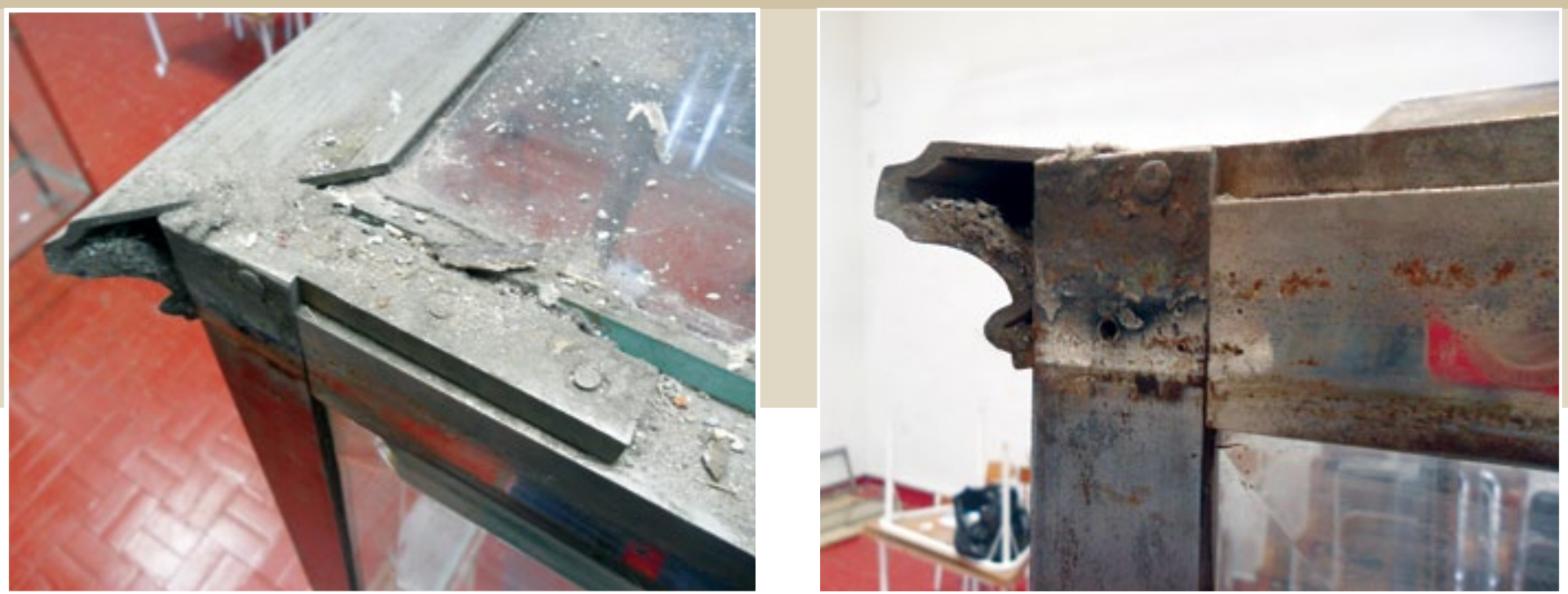

naturaleza, sufría distintos grados de corrosión (Figura 5). Se detectaron desajustes estructurales que ocasionaban separación entre los vidrios y las molduras, así como problemas en el desempeño de las bisagras y los sistemas de cerraduras. Además, los vidrios estaban sucios, tenían manchas de pintura en superficie y pequeñas zonas desportilladas.

Se realizaron procesos de limpieza superficial en seco y húmedo para eliminar productos ajenos tanto en las secciones de metal como en las hojas de vidrio, cuyos bordes se protegieron para evitar que se friccionaran con las molduras en que se insertan. Para solventar los desajustes estructurales fue necesario desarmar y rearmar las partes afectadas. Asimismo, se removieron los productos de corrosión presentes y se realizó el proceso de pasivación, para culmi- nar con la aplicación de una capa de protección. Aunque estos tratamientos directos no fueron complejos, la intervención de las vitrinas implicó tres problemáticas: la primera, la dificultad en el manejo de obra de grandes dimensiones y alta fragilidad; la segunda —relativa al ámbito de precauciones-, la toxicidad a la que se expuso a los restauradores y al resto de los trabajadores del museo durante la limpieza de los productos de corrosión, llevada a cabo en un lugar no adecuado para ello, y la tercera, las limitantes derivadas de intervenir sólo una parte de una colección que debe tratarse como unidad.

No obstante lo anterior, los resultados de los procesos técnicos de restauración fueron significativos tanto en términos estéticos e históricos como funcionales, y llevaron a plantear interrogantes en relación con el uso y la concepción de las vitrinas en el pasado y en el presente, las cuales corresponden al ámbito de la intervención teórica.

Como ya se mencionó, originalmente las vitrinas se diseñaron y utilizaron como parte del mobiliario de las salas de exhibición del MNA$\mathrm{HE}$, es decir, no se construyeron para mostrarse por sí solas, sino para que fungieran como continente de su importante contenido: los objetos que dentro de ellas debían mostrarse y lucir en virtud de su papel protagónico en la exhibición. Como tales —se trata de muebles de buena calidad evidente y estéticamente muy bien logrados-, su contribución al diseño expositivo no era necesariamente irrelevante, aunque la función que cumplían indudablemente era secundaria (Figura 6). Hoy en día esta condición ha cambiado: 


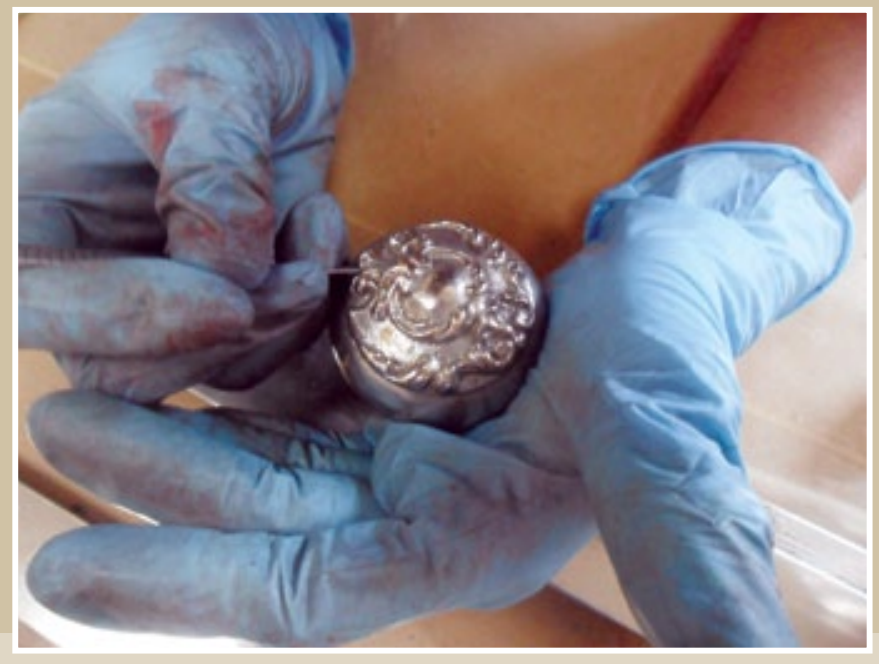

FIGURA 6. Intervención en detalles estéticos de una de las vitrinas: perilla (Cortesía: Proyecto Conservación y Restauración de las Colecciones del Museo Nacional de las Culturas en el Marco de su Reestructuración 2010-2011, CNCPC-INAH, 2011).

FIGURA 7. Elementos tecnológico-funcionales de una de las vitrinas: bisagras (Cortesía: Proyecto Conservación y Restauración de las Colecciones del Museo Nacional de las Culturas en el Marco de su Reestructuración 20102011, CNCPC-INAH, 2011).

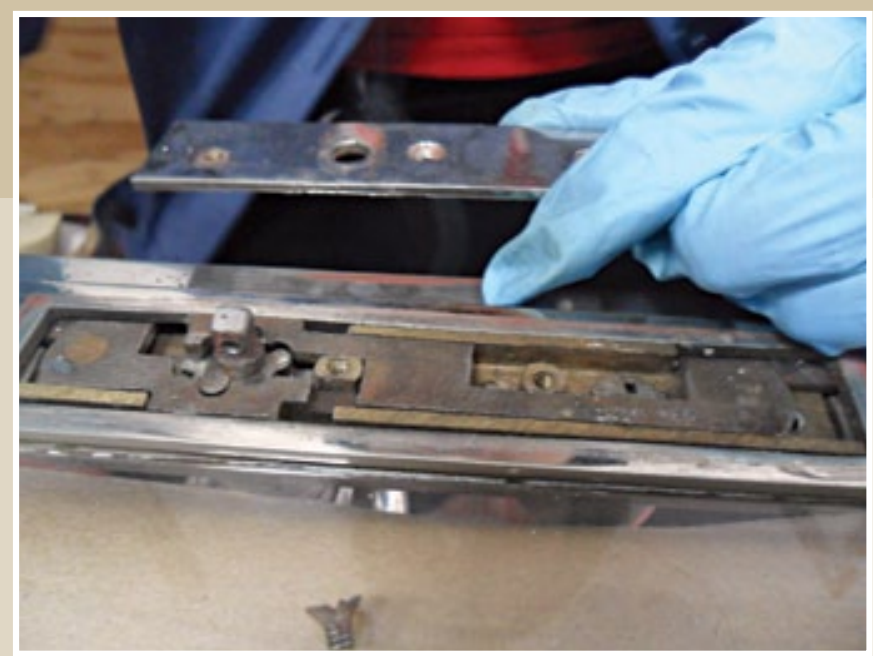

una vez que han trascendido en el tiempo las vitrinas pueden concebirse, por propio derecho, como bienes culturales de la historia museológica mexicana. Se trata, por tanto, de un ejemplo claro de revaloración sincrónica, durante la cual un artefacto adquiere un nuevo significado y, con ello, queda transformada su conceptualización.

¿Qué significa esta reconfiguración de los valores históricos, estéticos y funcionales de las vitrinas? Sin duda, una nueva aproximación a su materialidad. Basta observar cada una de ellas para descubrir información tecnológico-funcional de la época en que se construyeron (Figura 7). Su propio diseño sirve para deducir datos, por un lado, sobre las características del montaje de las salas del MNAHE y, por el otro, acerca de la visión que sus especialistas tenían sobre las exhibiciones.

En este sentido, el trabajo de conservación-restauración de las dos vitrinas aquí expuesto puede considerarse un valioso preámbulo no sólo para trazar nuevas pautas para la futura intervención material de todo el conjunto, sino también para establecer líneas de investigación histórica sobre las evidencias materiales concretas del desarrollo museológico mexicano.

\section{Agradecimientos}

El desarrollo de este proyecto fue posible gracias al apoyo de la CNCPCINAH, particularmente de su subdirectora de Talleres de Conservación e Investigación, la restauradora Dora Méndez, así como de las autoridades del MNC en 2011: su director, el antropólogo Leonel Durán Solís, y su subdirector de Catalogación y Documentación de Colecciones, el geógrafo Luis Felipe Crespo Oviedo. Un agradecimiento especial a la doctora Isabel Medina-González por su ayuda en la definición y edición de este artículo.

Intervención agradece al Sistema Nacional de Fototecas (SINAFO) del INAH, las imágenes del Museo Na- cional de Arqueología, Historia y Etnografía, empleadas para la ilustración y pleca (número de inventario 420630 y 42464912 ) de esta contribución.

\section{Referencias}

Ramírez Galván, Adriana, Damaris Aguilar Jiménez, Laura I. Martínez Rodríguez, Berenice Mejía Maldonado y Patricia Ruiz Portilla

2011 Reporte de intervención de conservación-restauración: Egipto, Medio Oriente, donaciones y vitrinas: Temporada de trabajo abril-mayo del 2011, mecanoescrito, México, CNCPC-INAH.

V.V. A.A.

2001 "El Museo Nacional en el imaginario mexicano", Alquimia 12.

Título en inglés: Continent/Content: new reflections on the former $\mathrm{Na}$ tional Museum's displays 